\title{
Differential Involvement of DI and D2 Dopamine Receptors in L-DOPA-Induced Angiogenic Activity in a Rat Model of Parkinson's Disease
}

\author{
Hanna S Lindgren*, ${ }^{, 1,2}$, K Elisabet Ohlin ${ }^{1,2}$ and M Angela Cenci*,1 \\ 'Basal Ganglia Pathophysiology Unit, Department of Experimental Medical Science, Lund University, Lund, Sweden
}

\begin{abstract}
Angiogenesis occurs in the brains of Parkinson's disease patients, but the effects of dopamine replacement therapy on this process have not been examined. Using rats with 6-hydroxydopamine lesions, we have compared angiogenic responses induced in the basal ganglia by chronic treatment with either L-DOPA, or bromocriptine, or a selective DI receptor agonist (SKF38393). Moreover, we have asked whether L-DOPA-induced angiogenesis can be blocked by co-treatment with either a DI - or a D2 receptor antagonist (SCH23390 and eticlopride, respectively), or by an inhibitor of extracellular signal-regulated kinases I and 2 (ERKI/2) (SL327). L-DOPA, but not bromocriptine, induced dyskinesia, which was associated with endothelial proliferation, upregulation of immature endothelial markers (nestin) and downregulation of endothelial barrier antigen in the striatum and its output structures. At a dose inducing dyskinesia ( $1.5 \mathrm{mg} / \mathrm{kg} / \mathrm{day})$, SKF38393 elicited angiogenic changes similar to L-DOPA. Antagonism of DI- but not D2 class receptors completely suppressed both the development of dyskinesia and the upregulation of angiogenesis markers. In fact, L-DOPA-induced endothelial proliferation was markedly exacerbated by low-dose D2 antagonism ( $0.01 \mathrm{mg} / \mathrm{kg}$ eticlopride). Inhibition of ERKI/2 by SL327 attenuated L-DOPA-induced dyskinesia and completely inhibited all markers of angiogenesis. These results highlight the specific link between treatment-induced dyskinesias and microvascular remodeling in the dopamine-denervated brain. L-DOPA-induced angiogenesis requires stimulation of DI receptors and activation of ERKI/2, whereas the stimulation of D2 receptors seems to oppose this response. Neuropsychopharmacology (2009) 34, 2477-2488; doi: I0.1038/npp.2009.74; published online I5 July 2009
\end{abstract}

Keywords: L-DOPA; dyskinesia; 6-OHDA; angiogenesis; blood-brain barrier; dopamine receptors

\section{INTRODUCTION}

An essential part of the brain is constituted by microvessels, which are intimately associated with glial cells and neurons. Abnormal vascular remodeling within the CNS occurs in a large number of pathological conditions (reviewed in Carmeliet, 2003; Zacchigna et al, 2008) and several neurodegenerative diseases, traditionally considered to result from neuronal defects, can today also be linked to vascular abnormalities and blood-brain barrier (BBB) disruption (Zacchigna et al, 2008). Parkinson's disease (PD) is characterized by a progressive degeneration of nigrostriatal

*Correspondence: Dr HS Lindgren, Basal Ganglia Pathophysiology Unit, Department of Experimental Medical Science, Lund University, BMC FI I, Lund, 22I 84, Sweden, Tel: + 46462224446 ,

Fax: + 4646 2224546, E-mail: Hanna.Lindgren@med.lu.se or

Professor MA Cenci, Basal Ganglia Pathophysiology Unit, Department of Experimental Medical Science, Lund University, BMC FII, Lund, 221 84, Sweden, Tel: + 4646 2221431, Tel: + 46462224546 ,

E-mail: Angela.Cenci_Nilsson@med.lu.se

${ }^{2}$ These authors contributed equally to this work

Received 7 December 2008; revised II June 2009; accepted 12 June 2009 dopamine (DA) neurons, causing typical motor symptoms (discussed in Cenci and Lundblad, 2006). Interestingly, postmortem examinations of parkinsonian brains have revealed increased number of endothelial cells in the substantia nigra (Faucheux et al, 1999) as well as altered expression of angiogenic cytokines in several basal ganglia nuclei (Yasuda et al, 2007). As all PD patients receive longterm treatment with dopaminergic drugs, it remains unclear whether the observed changes represented an angiogenic response to the neurodegenerative disease or to its pharmacotherapy. Working on a rat model of PD, we have found that treatment with L-DOPA causes endothelial proliferation, loss of BBB integrity, and an expansion of the microvascular bed in several basal ganglia nuclei (Westin et al, 2006). Such alterations were found to positively correlate with the severity of dyskinesia (abnormal involuntary movements) induced by the treatment (Westin et al, 2006). Endothelial proliferation and altered BBB permeability can potentially affect the kinetics of LDOPA entry into the affected brain regions, favoring the occurrence of motor complications. Indeed, large and rapid fluctuations in brain levels of L-DOPA and DA have a prime pathophysiological role in L-DOPA-induced 
dyskinesia (LID) and motor fluctuations (discussed in Cenci, 2007; Cenci and Lindgren, 2007; Cenci and Lundblad, 2006; Chase, 1998).

Rats with stable 6-hydroxydopamine (6-OHDA) lesions of the medial forebrain bundle provide a Parkinson's model with negligible neuroinflammation processes (Lindgren et al, 2007), and angiogenesis in the basal ganglia (Westin et al, 2006). In this animal model, microvascular alterations induced by the pharmacological treatment can be clearly dissected and correlated to behavioral responses. In this study, we have compared angiogenic responses induced by L-DOPA or bromocriptine, the prototype anti-parkinsonian agent with low dyskinesiogenic potential (Lees and Stern, 1981; Pearce et al, 1998; Rascol et al, 1979). Both L-DOPA and bromocriptine have a marked motor stimulant effect in animal models of PD, but the motor activation produced by bromocriptine does not involve dyskinesia (Lundblad et al, 2002; Pearce et al, 1998). This allowed us to ask the question, whether an increased motor activity per se may bring about microvascular remodeling in the basal ganglia, in analogy to the exercise-induced angiogenesis reported in other brain regions (Ekstrand et al, 2008a; Kleim et al, 2002; Swain et al, 2003). As bromocriptine exerts its motor stimulant ('anti-akinetic') effects predominantly by acting on the D2 receptor (Kvernmo et al, 2006; Perachon et al, 1999), it yields a different profile of DA receptor activation compared with L-DOPA. We thus addressed the specific role of D1- vs D2-like DA receptors in mediating angiogenic responses to treatment. To this end, we examined the effects of a selective D1 receptor agonist, as well as those of specific D1- or D2-like receptor antagonists co-administered with L-DOPA. An additional group of rats received combined treatment with L-DOPA and SL327, a specific inhibitor of extracellular signal-regulated kinases 1 and 2 (ERK1/2) activation. Taken together, our results show that PD treatments increasing motor activity do not necessarily induce angiogenesis in the basal ganglia. This response requires stimulation of D1 receptors and activation of ERK1/2, and it is intimately linked with the development of dyskinesia.

\section{MATERIALS AND METHODS}

\section{Animals}

Female Sprague-Dawley rats $(220-225 g$; Harlan, The Netherlands) were housed in a $12 \mathrm{~h}$ light-dark cycle with food and water ad libitum. All experiments were performed on rats with nearly complete, unilateral 6-OHDA lesions of the medial forebrain bundle performed per our standard procedures (Cenci et al, 1998; further information in Supplementary Material-materials and methods). All procedures were approved by the Malmö-Lund Ethical Committee on Animal Research.

\section{Drugs}

L-DOPA methyl ester, benserazide- $\mathrm{HCl}$, bromocriptine, SKF38393, SCH23390, 5-bromo-2'-deoxyuridine (BrdU), and eticlopride were purchased from Sigma-Aldrich Sweden AB (Stockholm, Sweden). The ERK1/2 inhibitor, SL 327 was bought from Ascent Scientific (Bristol, UK). All drugs were freshly dissolved in saline $(0.9 \% \mathrm{NaCl})$, but for bromocriptine, SL327 and BrdU. Bromocriptine was mixed with an equal weight of tartaric acid and two drops of $99 \%$ ethanol, and dissolved in sterile water. SL327 was dissolved in a sterile water solution of $70 \%$ DMSO. To label mitotic cells, all rats received bi-daily injections of $\mathrm{BrdU}(50 \mathrm{mg} / \mathrm{kg})$ dissolved in phosphate-buffered saline (PBS), during the last 3 days of drug treatment. All injections of L-DOPA also delivered benserazide at the fixed dose of $15 \mathrm{mg} / \mathrm{kg}$.

\section{Experimental Design and Pharmacological Treatments}

This study comprised four different experiments and their time course and treatment regimen are illustrated in Supplementary Material, Supplementary Figure S1.

Experiment 1. Rats $(n=18)$ were allocated to three groups, receiving L-DOPA $(6 \mathrm{mg} / \mathrm{kg}$, bi-daily; $n=7)$, bromocriptine $(2.5 \mathrm{mg} / \mathrm{kg}$, single daily; $n=6)$, or saline for 21 days $(n=5)$. At these doses and administration regimens, bromocriptine and L-DOPA produce the same overall amount of motor activation and the same degree of improvement in forelimb akinesia (Lindgren et al, 2007; Lundblad et al, 2002). As the temporal course of bromocriptine-induced motor activation is delayed (Lindgren et al, 2007; Lundblad et al, 2002), bromocriptine was injected $2 \mathrm{~h}$ before behavioral testing.

Experiment 2. Rats $(n=30)$ received daily injections of either L-DOPA $(10 \mathrm{mg} / \mathrm{kg} ; n=8)$ or the D1 agonist SKF38393, given at the doses of $0.5 \mathrm{mg} / \mathrm{kg}$ ('SKF low'; $n=7$ ), or $1.5 \mathrm{mg} / \mathrm{kg}$ ('SKF high'; $n=8$ ). A control group was injected with vehicle ('saline'; $n=7$ ). The higher dose of SKF38393 was expected to have motor stimulant properties similar to $10 \mathrm{mg} / \mathrm{kg}$ L-DOPA (LaHoste and Marshall, 1990; Monville et al, 2005), whereas the lower dose was chosen not to cause significant motor activation (Pollack and Fink, 1996).

Experiment 3. Rats $(n=40)$ were allocated to five treatment groups: (1) 'L-DOPA only' ( $10 \mathrm{mg} / \mathrm{kg} ; n=8)$; (2) L-DOPA combined with the D1 receptor antagonist, SCH23390 ('SCH23390'; $n=6$ ) at the dose of $0.25 \mathrm{mg} / \mathrm{kg}$ (Taylor et al, 2005; Westin et al, 2007); (3 and 4) L-DOPA combined with the D2 antagonist, eticlopride at either $0.01 \mathrm{mg} / \mathrm{kg}$ ('eticlopride low', $n=7$ ) or $2 \mathrm{mg} / \mathrm{kg}$ ('eticlopride high'; $n=7$ ). The low dose and high dose were chosen in order not to interfere with normal motor activity (Bardo et al, 1999; Schindler and Carmona, 2002), or to reduce dyskinesia (Taylor et al, 2005), respectively. The DA antagonists were given $30 \mathrm{~min}$ before the daily L-DOPA/benserazide injection. Controls received either saline alone $(n=4)$, or saline preceded by the higher dose of the D1 or D2 antagonist $(n=4+4)$. As these control treatments produced identical behavioral and histological profiles, they were later pooled into one single group ('saline'; $n=12$ ).

Experiment 4. Rats $(n=19)$ received daily treatment with, (1) L-DOPA and the DMSO/water vehicle ('L-DOPA', $10 \mathrm{mg} /$ $\mathrm{kg}, n=5$ ); (2) L-DOPA and $100 \mathrm{mg} / \mathrm{kg}$ SL-327 ('SL low', $n=4$ ); (3) L-DOPA and $300 \mathrm{mg} / \mathrm{kg} \mathrm{SL327} \mathrm{('SL} \mathrm{high',} n=4$ ); and (4) saline preceded by the DMSO/water vehicle $(n=3)$ or by $300 \mathrm{mg} / \mathrm{kg}$ SL327 $(n=3)$. Both subgroups showed 
identical behavioral and histological profiles, and were later pooled into one single control group ('saline', $n=6$ ). The doses of SL327 were chosen based on a preliminary experiment evaluating their effects on L-DOPA-induced ERK1/2 activation in striatal neurons (Supplementary Material, Supplementary Figure S3). L-DOPA treatment was administered on 3 consecutive days, a time sufficient to detect an angiogenic response (Westin et al, 2006). SL327 was administered $20 \mathrm{~min}$ before each L-DOPA injection.

\section{Behavioral Tests}

Abnormal involuntary movement ratings. The development of L-DOPA-induced abnormal involuntary movements (AIMs) was monitored according to our standard procedures by an experimentally blinded investigator. Briefly, each rat was observed for 1 min every 20 min during $3 \mathrm{~h}$ after drug administration and scored on a scale from 0 to 4 on each of three AIM subtypes (axial, orolingual, and forelimb). Detailed descriptions of the rating scales are given in Cenci and Lundblad (2007). The AIMs are expressed as the sum of scores per testing session.

Automated recordings of rotation. The total amount of motor activation produced by L-DOPA or bromocriptine (experiment 1) was assessed by measuring rotational behavior on one occasion during the treatment (cf. Figure 1b). Rats were placed in hemispherical bowls directly after the L-DOPA injection or $120 \mathrm{~min}$ after the bromocriptine injection. The total number of rotations during the drug-active period provided a measure of the overall motor activation during 1 day of treatment (the drug-active period being, $3.5 \mathrm{~h} /$ dose $\times 2$ doses/day for L-DOPA, and $7 \mathrm{~h} /$ dose $\times$ 1 dose/day for bromocriptine).

\section{Tissue Preparation}

At $24 \mathrm{~h}$ after the last drug injection, rats were anaesthetized and transcardially perfused as described in Westin et al (2006). Brains were sectioned coronally on a freezing microtome at $40 \mu \mathrm{m}$ thickness and free-floating sections were stored in cryoprotective solution at $-20^{\circ} \mathrm{C}$ until further processing.

\section{Immunohistochemistry}

Bright-field immunohistochemistry was performed using a peroxidase-based detection method and $3^{\prime} 3^{\prime}$-diaminobenzidine (DAB; Sigma-Aldrich, Sweden AB) as the chromogen. Dual antigen immunofluorescence was performed as described in Westin et al (2006) to visualize BrdU-labeled nuclei within the laminin-positive endothelial coating of blood vessels. For a list of antibodies used, see Supplementary Material.

\section{Counts of BrdU/Laminin-Positive Cells}

In the first experiment, endothelial cell proliferation was quantified in the caudate-putamen $(\mathrm{CPu})$, globus pallidus (GP), entopeduncular nucleus (EP), and substantia nigra pars reticulata ( $\mathrm{SNr}$ ). In the subsequent experiments, quantification was limited to the regions with most
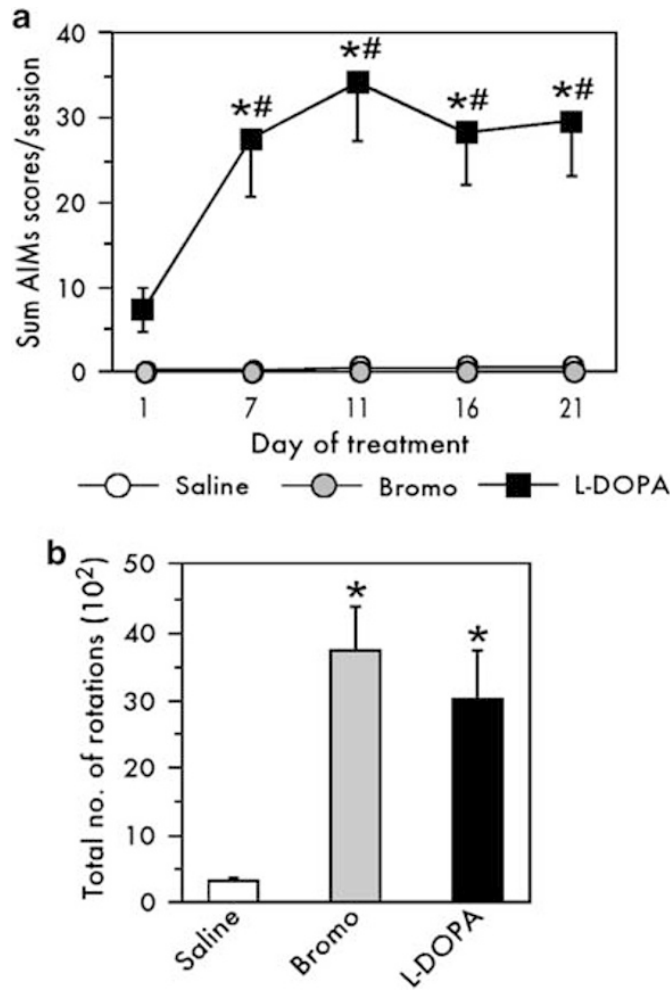

Figure I Evaluation of abnormal involuntary movements (AIMs) and total motor activity. (a) Bi-daily chronic L-DOPA treatment ( $6 \mathrm{mg} / \mathrm{kg} ; n=7$ ) but not bromocriptine $(2 \mathrm{mg} / \mathrm{kg} ; n=6)$-induced AIMs during the 21 days of treatment. Scores are shown as the sum of axial, limb, and orolingual on each testing session. (b) L-DOPA and bromocriptine produced comparable levels of motor activity assessed as sum of full turns during the drug active period on the seventh day of treatment $(p<0.05$ vs * saline controls $(n=5)$, vs ${ }^{\#}$ bromocriptine). (a) Post hoc comparison with Tukey's HSD test after repeated-measures ANOVA $\left(F_{(2,15)}=15.74\right)$; (b) post hoc comparisons with Student-Newman-Keuls test after one-factor ANOVA $\left(F_{(2,15)}=5.14\right)$.

pronounced angiogenesis, that is, the EP and the SNr. The number of BrdU/laminin-positive cells was counted from two-three sections per structure under a Nikon Eclipse 80i microscope equipped with a dual fluorescence filter. The analysis was done using a $\times 40$ objective and a grid providing a sampling frame of $0.25 \times 0.25 \mathrm{~mm}$. The lateral part of the $\mathrm{CPu}$ was sampled at anterior-posterior (AP) levels, 0.40 to $-0.48 \mathrm{~mm}$ from bregma, whereas analysis of the GP (AP: -0.8 to -1.3 ), EP (AP: -2.12 to -3.14 ), and $\mathrm{SNr}$ (AP: -5.2 to -5.9 ) covered the entire cross-sectional area (Paxinos and Watson, 1998). The total areas sampled were as follows: $\mathrm{CPu}, 2 \mathrm{~mm}^{2}$; $\mathrm{GP}, 0.5 \mathrm{~mm}^{2}$; $\mathrm{EP}, 0.375 \mathrm{~mm}^{2}$, and $\mathrm{SNr}$, $1 \mathrm{~mm}^{2}$. We counted only BrdU-labeled cell nuclei located within the laminin-positive endothelial lining of the microvessels. To facilitate regional comparisons, data are presented as number of cells per square millimeter after correction for split cell counts (Abercrombie and Johnson, 1946).

\section{Markers of Angiogenesis and BBB Integrity}

Immunoreactivities for nestin and endothelial barrier antigen (EBA) were measured selectively on microvessels using image segmentation (Visiopharm Integrator System; Visiopharm, Hoersholm, Denmark), as extensively de- 
scribed in Westin et al (2006). See Supplementary Material for a brief introduction to the method.

\section{Global Spatial Sampling of Blood Vessel Length}

Every fourth section through the EP and SNr was stained for RECA-1 to estimate the total length of microvessels by computer-assisted stereology (CAST, version 2.3.2.0; Visiopharm, Hoersholm, Denmark) with computer-generated isotropic virtual planes (Larsen et al, 1998) as described in Westin et al (2006). Analysis was performed using a $\times 40$ objective in a Nikon Eclipse 80i microscope with a motorized stage, controlling movements in the $x$ - and $y$ axes. A three-dimensional sampling box consisting of a counting frame (frame area $5502 \mu \mathrm{m}^{2}$; sampling box height of $10 \mu \mathrm{m}$; guard area $3 \mu \mathrm{m}$ ) was focused through the section in which virtual planes were generated at a fixed plane separation of $10 \mu \mathrm{m}$. In each animal, 100-150 blood vessel intersections were counted on both lesioned and intact sides of the structures analyzed. An unbiased stereological assessment of the global length, $L$, is as follows:

$$
L=2 \frac{p(\text { box })}{a(\text { plane })} \frac{\sum Q}{\sum P_{\text {ref }}} V_{\text {ref }}
$$

where $Q$ is the total sum of intersections, $p$ (box) is the number of corners in one three-dimensional box, $\Sigma P_{\text {ref }}$ is the sum of all of the points hitting the reference space, and $a$ (plane) is the average of the sum of areas of isotropic oriented planes. The volume of the three-dimensional box divided by the distance between the planes is equal to $a$ (plane). $V_{\text {ref }}$ is the total volume of the reference space measured with Cavalieri's principle (Gundersen and Jensen, 1987).

\section{Statistical Analysis}

All data are presented as group means \pm SEM. The AIM scores per testing session during the chronic drug treatment periods were analyzed using repeated-measures ANOVA. Relevant pairwise differences were analyzed by post hoc Tukey's honestly significant difference (HSD) test. Blood vessel lengths were analyzed by two-factor ANOVA and post hoc Tukey's HSD test, whereas counts of BrdU/lamininpositive cells and other microvascular markers were analyzed by one-factor ANOVA and post hoc StudentNewman-Keuls test. The threshold for statistical significance was set at $\alpha=0.05$. Precise $p$-values from the ANOVA will be reported in the text, whereas post hoc comparisons will be reported as being significant $(p<0.05)$ or nonsignificant.

\section{RESULTS}

\section{Angiogenesis is Induced by L-DOPA but not Bromocriptine}

In experiment 1, rats receiving L-DOPA developed AIMs, whereas those treated with bromocriptine exhibited pronounced rotational activity in the absence of dyskinesialike behaviors (Figure 1a and b). L-DOPA-treated rats showed significantly higher AIM scores compared with bromocrip- tine-treated animals and saline controls starting from the second testing session through the end of treatment (repeated-measures ANOVA; $p_{\text {treatment }}=0.002, p_{\text {time }}<0.001$ and $\left.p_{\text {interaction }}<0.001\right)$. Bromocriptine-treated rats did not differ from saline-injected controls at any testing session (Figure 1a). Automated recordings of rotational behavior were carried out to ascertain that L-DOPA and bromocriptine had induced similar overall levels of motor activation. As shown in Figure $1 \mathrm{~b}$, the sum of both ipsilateral and contralateral rotations during the drug-active periods did not differ between the two drug-treated groups, but were significantly increased compared with saline-treated controls ( $p<0.05$ for L-DOPA and bromocriptine $v s$ saline).

Counts of double-labeled BrdU- and laminin-positive cells were performed in the $\mathrm{CPu}, \mathrm{GP}, \mathrm{EP}$, and $\mathrm{SNr}$ in both hemispheres. On the side contralateral to the lesion, the number of BrdU/laminin-immunopositive cells did not differ among groups in any region examined (data not shown), which is in line with earlier findings (Westin et al, 2006). In the DA-depleted hemisphere, the number of BrdU/lamininpositive cells was significantly higher in all regions in L-DOPAtreated rats compared with both bromocriptine and saline controls (Table 1 and Supplementary Figure S2A; one-factor ANOVA, $\left.p_{\mathrm{CPu}}=0.008 ; p_{\mathrm{GP}}=0.010 ; p_{\mathrm{EP}}=0.004 ; p_{\mathrm{SNr}}=0.005\right)$.

Endothelial expression of nestin has been associated with angiogenesis in the adult brain (Alonso et al, 2005; Mokry and Nemeneck, 1999; Westin et al, 2006). As nestin also can be expressed by neuroepithelium-derived progenitor cells (Frederiksen and McKay, 1988; Gallo and Armstrong, 1995), nestin-immunoreactivity was only measured on blood vessels. The number of nestinimmunopositive vessel profiles on the lesioned side was significantly elevated in the $\mathrm{CPu}, \mathrm{GP}, \mathrm{EP}$, and $\mathrm{SNr}$ in rats treated with L-DOPA compared with bromocriptine and saline (Table 1; Figure 2a-d). The effect was particularly pronounced in the basal ganglia output structures (EP and $\mathrm{SNr}$ in Table 1; Figure $2 \mathrm{c}$ and d), where levels were four- to sevenfold larger in the L-DOPA group compared with the other treatments (Table 1; Figure 2a-1; one-factor ANOVA, $\left.p_{\mathrm{CPu}}=0.001 ; p_{\mathrm{GP}}=0.002 ; p_{\mathrm{EP}}=0.002 ; p_{\mathrm{SNr}}<0.001\right)$.

Endothelial barrier antigen (EBA) is a triplet of proteins expressed on blood vessels with fully developed $\mathrm{BBB}$ properties, providing a marker of BBB integrity (Cassella et al, 1996; Rosenstein et al, 1998). In bromocriptine- and saline-treated animals, EBA-immunoreactive vessels were evenly distributed in all structures on both sides with densities that reflected regional differences in vascularization (cf. saline control, Figure 2u-x; Cavaglia et al, 2001). By contrast, L-DOPA-treated animals showed areas lacking EBAimmunoreactive vessels on the DA-depleted side (Table 1; Figure $2 \mathrm{~m}-\mathrm{p}$; one-factor ANOVA, $p_{\mathrm{GP}}=0.018, p_{\mathrm{EP}}=0.010$, $\left.p_{\mathrm{SNr}}=0.001\right)$. In concordance with the other markers, the most clear-cut difference between groups occurred in the EP and $\mathrm{SNr}$, where L-DOPA-treated animals showed a loss of EBA-positive profiles by nearly $25 \%$ compared with saline and bromocriptine rats (Figure 2, cf. o-p with s-t and $\mathrm{w}-\mathrm{x}$ ).

To confirm that the increased expression of angiogenesis markers produced by L-DOPA was associated with actual growth of blood vessels, total microvessel lengths were estimated in the EP and $\mathrm{SNr}$ using an unbiased stereological method (Larsen et al, 1998). A significant overall difference between groups was revealed by two-factor ANOVA 
Table I Angiogenesis markers in experiment I

\begin{tabular}{|c|c|c|c|}
\hline & L-DOPA & Bromocriptine & Saline \\
\hline \multicolumn{4}{|l|}{ Striatum } \\
\hline BrdU/laminin & $22.16 \pm 2.5^{*}, \#$ & $13.20 \pm 2.4$ & $8.16 \pm 2.3$ \\
\hline Nestin & $2.64 \pm 0.47^{*}, \#$ & $0.76 \pm 0.09$ & $0.87 \pm 0.22$ \\
\hline EBA & $0.97 \pm 0.02$ & $0.96 \pm 0.02$ & $0.98 \pm 0.02$ \\
\hline \multicolumn{4}{|l|}{ GP } \\
\hline BrdU/laminin & $83.00 \pm 12.8^{*, \#}$ & $42.00 \pm 6.9$ & $25.60 \pm 8.8$ \\
\hline Nestin & $2.11 \pm 0.17^{*, \#}$ & $0.98 \pm 0.29$ & $1.07 \pm 0.14$ \\
\hline EBA & $0.78 \pm 0.05^{*}, \#$ & $1.07 \pm 0.09$ & $0.97 \pm 0.02$ \\
\hline \multicolumn{4}{|l|}{$E P$} \\
\hline BrdU/laminin & $98.00 \pm 23.5^{*, \#}$ & $22.33 \pm 5.1$ & $16.00 \pm 6.3$ \\
\hline Nestin & $8.83 \pm 2.75^{*, \#}$ & $1.36 \pm 0.33$ & $1.06 \pm 0.29$ \\
\hline EBA & $0.75 \pm 0.06$ **\# & $1.10 \pm 0.04$ & $1.06 \pm 0.11$ \\
\hline \multicolumn{4}{|l|}{ SNr } \\
\hline BrdU/laminin & $93.33 \pm 24.9^{*, \#}$ & $33.56 \pm 7.3$ & $12.80 \pm 4.8$ \\
\hline Nestin & $5.52 \pm 0.99 *$ & $0.79 \pm 0.24$ & $1.28 \pm 0.27$ \\
\hline EBA & $0.77 \pm 0.04 *, \#$ & $0.97 \pm 0.02$ & $1.04 \pm 0.05$ \\
\hline
\end{tabular}

L-DOPA but not bromocriptine induced microvascular changes in the basal ganglia. Endothelial cell proliferation (expressed as number of BrdU/lamininpositive cells $/ \mathrm{mm}^{2}$ ) as well as nestin expression on blood vessel profiles (expressed as percentage of contralateral (intact) side in each group) were upregulated in L-DOPA-treated rats $(n=7)$ compared with bromocriptine$(n=6)$ and saline-treated controls $(n=5)$ in the basal ganglia. The percentage of EBA-immunopositive blood vessels (expressed as percentage of intact side) was reduced only in L-DOPA animals compared with the other two groups. Onefactor ANOVA, $p<0.05$ vs; * saline, \# vs bromocriptine; one-factor ANOVA and post hoc Student-Newman-Keuls test). BrdU; $\mathrm{F}_{\mathrm{CPu}(2.15)}=6.84$,

$F_{\mathrm{GP}(2,15)}=6.28, \mathrm{~F}_{\mathrm{EP}(2,15)}=7.98$ and $\mathrm{F}_{\mathrm{SNr}(2,15)}=7.89$. Nestin: $\mathrm{F}_{\mathrm{CPu}(2,15)}=$

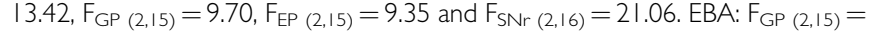
$5.28, F_{\operatorname{EP}(2,15)}=6.35$ and $F_{S N r}(2,15)=16.97$.

$\left(\mathrm{SNr}: p_{\text {treatment }}=0.005, p_{\text {side }}=0.706\right.$, and $p_{\text {interaction }}=0.040$; EP: $p_{\text {treatment }}=0.020, p_{\text {side }}=0.249$, and $\left.p_{\text {interaction }}=0.004\right)$. On the DA-depleted side, the total microvascular lengths were significantly larger in L-DOPA-treated rats compared with bromocriptine-treated animals and saline-injected controls (Table 2). Moreover, only L-DOPA-treated animals showed a significant, within-group difference between the sides $(P<0.05$ for lesioned $v s$ intact side in both EP and $\mathrm{SNr}$ ). A comparison between L-DOPA and saline animals on the side ipsilateral to the lesion revealed an absolute increase in total microvessel lengths by $\sim 4 \mathrm{~cm}$ in the EP (total volume of the structure $\sim 0.3 \mathrm{~mm}^{3}$ ) and by $\sim 20 \mathrm{~cm}$ in the $\mathrm{SNr}$ (total volume $\sim 1.8 \mathrm{~mm}^{3}$ ).

\section{Chronic Treatment with a D1 Receptor Agonist Induces Angiogenesis and Dyskinesia}

We next compared the angiogenic effects of L-DOPA with those of the selective D1-receptor agonist SKF38393. Rats with a 6-OHDA lesion were chronically treated with either L-DOPA or SKF38393 at two different doses $(0.5 \mathrm{mg} / \mathrm{kg}$, 'SKF low' or $1.5 \mathrm{mg} / \mathrm{kg}$, 'SKF high'). An overall comparison of AIM scores with repeated-measures ANOVA revealed pronounced differences between treatment groups and testing sessions (Figure $3 \mathrm{a} ; p_{\text {treatment }}<0.001$, $p_{\text {time }}<0.001$, and $\left.p_{\text {interaction }}<0.001\right)$. While the low dose of SKF38393 did not induce AIMs (Figure $3 \mathrm{a})$, the higher dose $(1.5 \mathrm{mg} / \mathrm{kg}$ ) induced a development of AIMs that was quantitatively and qualitatively indistinguishable from that induced by $10 \mathrm{mg} /$ $\mathrm{kg}$ L-DOPA (Figure 3a). Both the L-DOPA group and the 'SKF high' group significantly differed from the 'SKF low' group and saline controls from the second testing session and until the end of the experiment.

Quantitative analyses of the microvascular markers were carried out in the two structures where the angiogenic effects of L-DOPA are most pronounced, that is, the EP and SNr. Counts of BrdU/laminin-positive cells (Figure 3b) revealed a four- to sixfold increase after treatment with L-DOPA or $1.5 \mathrm{mg} / \mathrm{kg}$ SKF38393, whereas the 'SKF low' group did not differ from saline controls (one-factor ANOVA, $p_{\mathrm{EP}}<0.001, p_{\mathrm{SNr}}<0.001$; Supplementary Figure S3D-E).

Analysis of nestin immunoreactivity on blood vessel profiles showed similar group differences (Figure 3c), consisting in a two- to threefold increase in the L-DOPA and 'SKF high' groups compared with the 'SKF low' group and saline controls in both structures examined (one-factor ANOVA, $p_{\mathrm{EP}}<0.001, p_{\mathrm{SNr}}=0.003$; Supplementary Figure S3I-J).

The levels of EBA immunostaining on microvessel profiles differed among the groups in both the EP and the $\mathrm{SNr}$ (Figure 3d; one-factor ANOVA, $p_{\mathrm{EP}}=0.037, p_{\mathrm{SNr}}=$ 0.001). Animals treated with low-dose SKF or saline showed an even distribution of EBA-immunoreactive microvessels in both the EP and the SNr (Figure 3d; Supplementary Figure S3K). In contrast, areas lacking EBA-immunopositive microvessels were evident in both structures in LDOPA- and high-dose SKF-treated rats (illustrated in Supplementary Material, Supplementary Figure S3). The loss of EBA was most pronounced in the SNr in the 'SKF high' group (Figure 3d; $p<0.05 v s$ both 'SKF low' and saline controls).

\section{Antagonism of D1 but not D2 Receptors Blocks Both Dyskinesia and the Angiogenic Response}

In a third experiment, we addressed the role of D1 vs D2 receptors in the behavioral and microvascular responses to L-DOPA. Rats with a 6-OHDA lesion were chronically treated with L-DOPA in combination with either the D1-like receptor antagonist, $\mathrm{SCH} 23390$ at an earlier characterized dose $(0.25 \mathrm{mg} / \mathrm{kg}$; Westin et al, 2007), or with the D2 antagonist, eticlopride at two doses ('eticlopride low', $0.01 \mathrm{mg} / \mathrm{kg}$; 'eticlopride high', $2.0 \mathrm{mg} / \mathrm{kg}$ ). An overall comparison of L-DOPA-induced AIM scores by repeatedmeasures ANOVA revealed highly significant differences between treatment groups and testing sessions (Figure $4 \mathrm{a}$; $p_{\text {treatment }}<0.001, \quad p_{\text {time }}<0.001$, and $\left.p_{\text {interaction }}=0.008\right)$. Animals treated with L-DOPA alone or L-DOPA plus $0.01 \mathrm{mg} / \mathrm{kg}$ eticlopride displayed similar AIM scores, differing significantly from both the $\mathrm{SCH} 23390$ and saline groups on all but the first testing session (Figure 4a). SCH23390treated animals did not differ from saline controls at any time point, indicating that LID had been completely blocked 

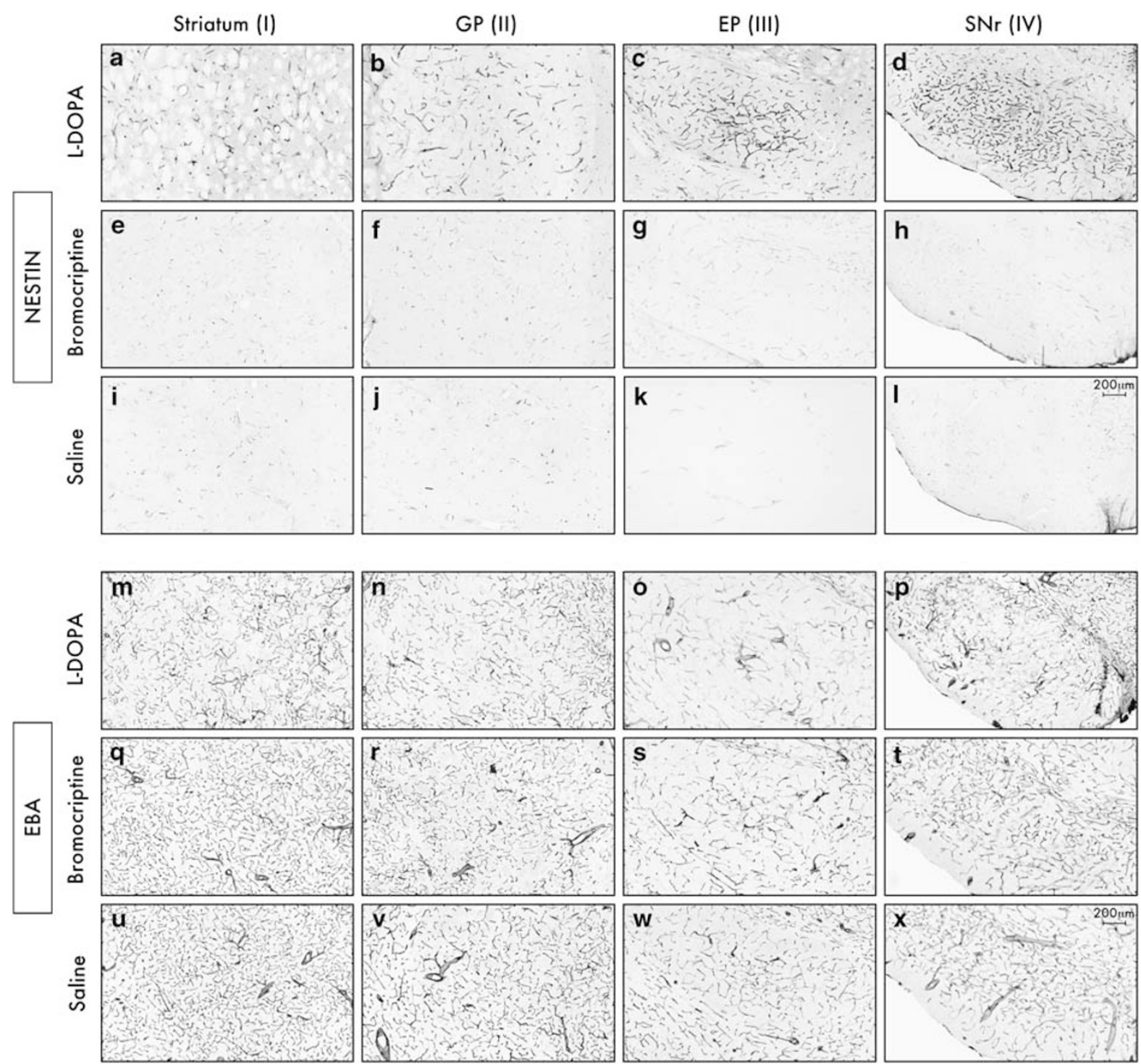

Figure 2 Bright-field photomicrographs of sections through the dorsal striatum (I), GP (II), EP (III), and SNr (IV) stained for markers of angiogenesis (nestin) and blood-brain barrier integrity (EBA). L-DOPA-treated animals showed increased expression of nestin (a-d) compared with bromocriptine- (e-h) and saline-treated controls $(i-l)$. In addition, loss of EBA expression was evident in the L-DOPA group ( $m-p)$ but not in bromocriptine- (q- $t$ ) and salinetreated controls $(u-x)$. Scale bar $=200 \mu \mathrm{m}$.

by the D1 antagonist (Figure 4a; $p<0.05$ for SCH23390 vs L-DOPA-only group from testing session 2). While the lower dose of the D2 antagonist had no effect on dyskinesia, $2 \mathrm{mg} /$ $\mathrm{kg}$ eticlopride reduced the AIM scores by $\sim 50 \%$ compared with L-DOPA alone $(p<0.05$ between 'eticlo high' and LDOPA-only groups on treatment days 11, 18, and 21; Figure 4a).

A similar pattern of group differences emerged from the analyses of angiogenic markers. The D1 antagonist blocked the $\mathrm{L}$-DOPA-induced increase in BrdU/laminin-positive cell numbers (Figure $4 \mathrm{~b}$; one-factor ANOVA, $p_{\mathrm{EP}}=0.001$, $\left.p_{\mathrm{SNr}}<0.001\right)$, as well as the upregulation of nestin (Figure $4 \mathrm{c} ; p_{\mathrm{EP}}=0.008, p_{\mathrm{SNr}}=0.006$ ) and the associated reduction in EBA immunoreactivity (Figure $4 \mathrm{~d} ; p_{\mathrm{EP}}=0.030$, $\left.p_{\mathrm{SNr}}=0.017\right)$. On each parameter examined, rats receiving combined treatment with $\mathrm{SCH} 23390$ and L-DOPA did not differ from saline-injected controls (cf. A and B, F and G, $\mathrm{K}$ and L in Supplementary Figure S3). By contrast, the D2 antagonist eticlopride did not block the angiogenic responses to L-DOPA. Indeed, the number of $\mathrm{BrdU} /$ laminin-positive cells was highest in animals treated with $0.01 \mathrm{mg} / \mathrm{kg}$ eticlopride plus L-DOPA compared with all other groups (Figure 4b; $p<0.05$ for 'eticlo low' $v s$ saline, SCH23390, and L-DOPA-only group in SNr). Changes in nestin expression were most pronounced in animals cotreated with eticlopride and L-DOPA, showing a two- to threefold upregulation of nestin-immunoreactive vessels in the EP and SNr compared with both the SCH23390 and saline groups (Figure 4c; Supplementary Figure $\mathrm{S3H}$ ). The reduction in EBA immunoreactivity produced by L-DOPA was not significantly affected by eticlopride (Figure $4 \mathrm{~d}$; cf. $\mathrm{M}$ and $\mathrm{N}$ in Supplementary Figure S3). 
Table 2 Total blood vessel lengths in experiment I

\begin{tabular}{llll}
\hline & L-DOPA & Bromocriptine & Saline \\
\hline EP & & & \\
Intact & $0.21 \pm 0.004$ & $0.22 \pm 0.008$ & $0.20 \pm 0.007$ \\
Lesion & $0.24 \pm 0.005^{*}, \#$ & $0.21 \pm 0.007$ & $0.21 \pm 0.004$ \\
SNr & & & \\
Intact & $1.53 \pm 0.04$ & $1.45 \pm 0.04$ & $1.54 \pm 0.04$ \\
Lesion & $1.65 \pm 0.08^{*}, \#$ & $1.43 \pm 0.02$ & $1.39 \pm 0.05$ \\
\hline
\end{tabular}

Total blood vessel length (expressed in meters) was increased on the lesioned side in both the EP and SNr of L-DOPA animals $(n=6)$ compared with the saline and bromocriptine group ( $p<0.05$ vs *saline-treated animal on the same side $(n=5)$, vs * bromocriptine-treated animals on the sameside $(n=6)$; two-factor ANOVA and post hoc comparisons with Tukey's HSD). EP: $F_{(2,28)}=$ 4.53, $\mathrm{SNr}: \mathrm{F}_{(2,32)}=6.20$.

Inhibition of ERK1/2 Signaling Blocks L-DOPA-Induced Angiogenesis

The Ras-ERK1/2 signaling pathway is a critical mediator of L-DOPA-induced neuroplasticity and dyskinesia (Santini et al, 2007; Schuster et al, 2008; Westin et al, 2007). To address the possible involvement of this pathway in L-DOPA-induced angiogenesis, 6-OHDA-lesioned rats were treated with L-DOPA preceded by either the mitogenactivated protein kinase kinase (MEK) inhibitor, SL327 or its vehicle. Two doses of the inhibitor were used ('SL low', $100 \mathrm{mg} / \mathrm{kg}$, and 'SL high', $300 \mathrm{mg} / \mathrm{kg}$ ), which produced a partial or total blockade of L-DOPA-induced phosphoERK1/2 expression in striatal neurons (see Supplementary Figure S4). For this study, we used a short regimen of L-DOPA treatment ( 3 days), which is sufficient to induce angiogenic activity (Westin $e t$ al, 2006) preceding the development of maximally severe AIMs (Westin et al, 2007; see also Figure 1a). An overall comparison of AIM scores revealed significant group differences over the 3-day treatment period (Figure 5a; $p_{\text {treatment }}=0.011, p_{\text {time }}=0.093$, and $p_{\text {interaction }}=0.136$ ). Rats treated with both the lower and the higher dose of SL327 showed overall reduced AIM severity, although the difference from L-DOPA-vehicle cases reached statistical significance only in the 'SL high' group in post hoc comparisons $(p<0.05$ for L-DOPA-only vs SL high on treatment day 2 and 3). All groups treated with L-DOPA differed significantly from saline-treated rats at all time points ( $p<0.05$ for saline $v s$ all other groups), further emphasizing that dyskinesia had not been totally abolished by SL327.

Interestingly, all markers of L-DOPA-induced angiogenesis were completely inhibited by SL327 co-treatment. In both the EP and SNr, the number of BrdU/lamininpositive cells was significantly higher in the L-DOPA-vehicle group compared with L-DOPA-SL327 or saline treatment (Figure $5 \mathrm{~b}$; one-factor ANOVA, $p_{\mathrm{EP}}<0.001, p_{\mathrm{SNr}}=0.001$; $p<0.05$ for L-DOPA only $v s$ all other groups), whereas the SL327 co-treated rats did not differ significantly from saline controls. A similar pattern emerged from the analysis of nestin and EBA expression. L-DOPA-vehicle treatment

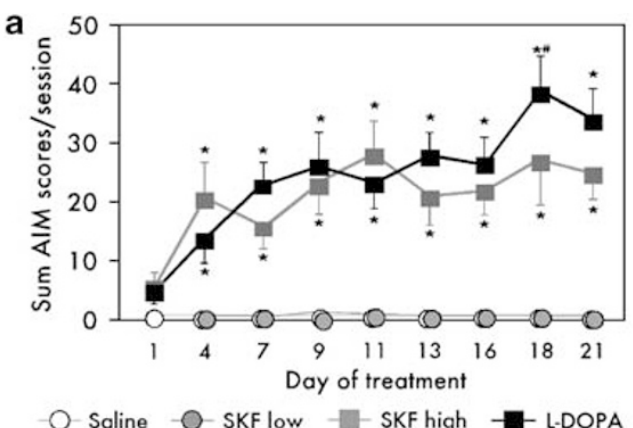

b $\quad \mathrm{EP} \quad \mathrm{SNr}$
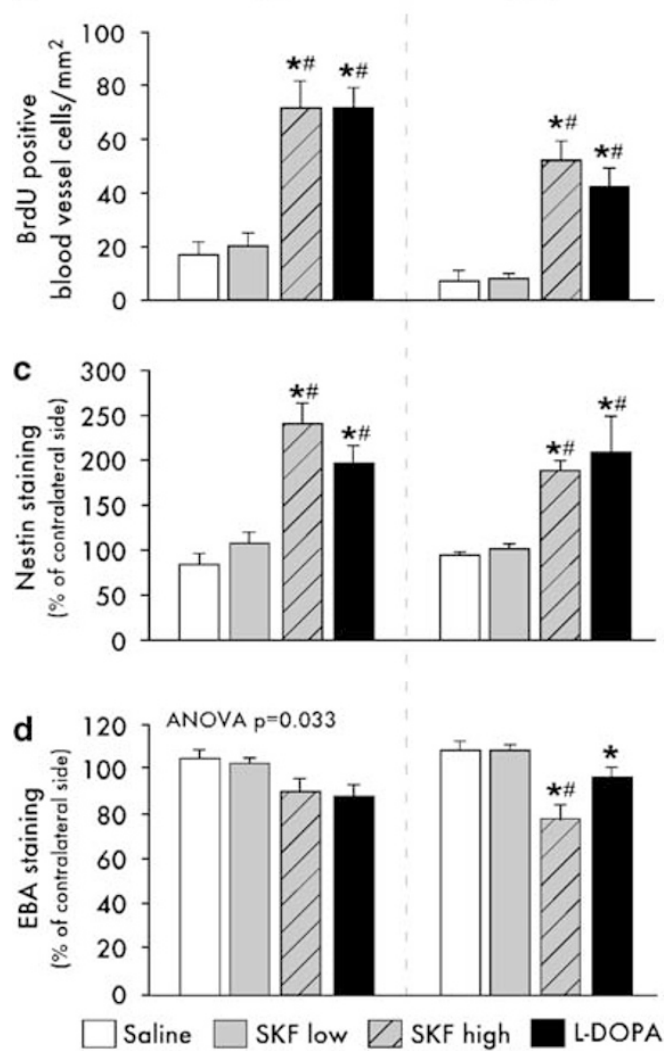

Figure 3 (a) Chronic L-DOPA ( $10 \mathrm{mg} / \mathrm{kg} ; n=8)$ and a high dose of the DI agonist SKF38393 $(1.5 \mathrm{mg} / \mathrm{kg})$ gradually induced AlMs during the 21 days of treatment. A lower dose of SKF38393 $(0.5 \mathrm{mg} / \mathrm{kg})$ did not induce dyskinesia. Scores are shown as a sum of axial, limb, and orolingual during each testing session (repeated-measures ANOVA: $p<0.05$ vs *saline controls $(n=7)$ and SKF38393 low dose $(n=7)$, " SKF38393 high dose $\left.(n=7) ; F_{(3,26)}=14.67\right)$. (b) The number of BrdU/laminin-positive cells/ $\mathrm{mm}^{2}$ was increased in EP and $\mathrm{SNr}$ in the groups exhibiting dyskinesia (L-DOPA and SKF38393 high dose). (c) These groups also show an increased expression of nestin on blood vessels on the lesioned side, expressed as percentage of contralateral side. (d) The same trends were evident with EBA immunoreactivity (one-factor ANOVA p-value represents a significant group effect, but the post hoc pairwise comparisons in the EP did not reach significance) (one-factor ANOVA: $p<0.05$ vs *saline controls $(n=7)$, vs ${ }^{\#}$ SKF38393 low dose $(n=7)$, BrdU: $F_{E P(3,26)}=15.04$ and $F_{S N r(3,26)}=13.16$ nestin: $F_{E P(3,26)}=12.03$ and $F_{S N r(3,26)}=5.92$. EBA: $\mathrm{F}_{\mathrm{EP}(3,26)}=3.28$ and $\left.\mathrm{F}_{\mathrm{SNr}(3,26)}=7.36\right)$.

produced a threefold upregulation of nestin on blood vessel profiles compared with either L-DOPA-SL327 or saline treatment (Figure $5 c$; one-factor ANOVA, $p_{\mathrm{EP}}=0.002$, $p_{\mathrm{SNr}}<0.001 ; p<0.05$ for L-DOPA only $v s$ all other groups). 
a

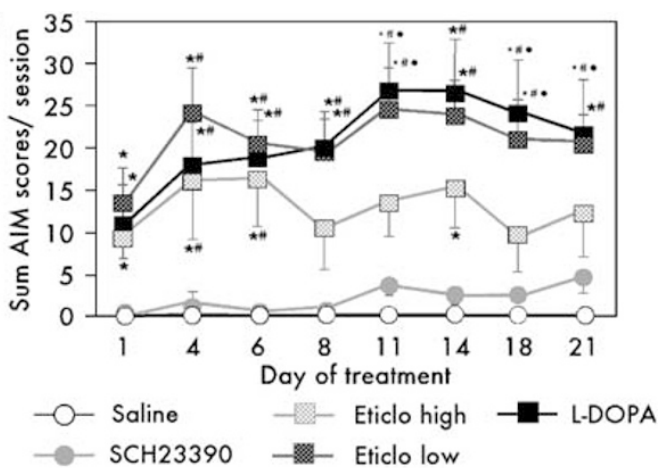

b
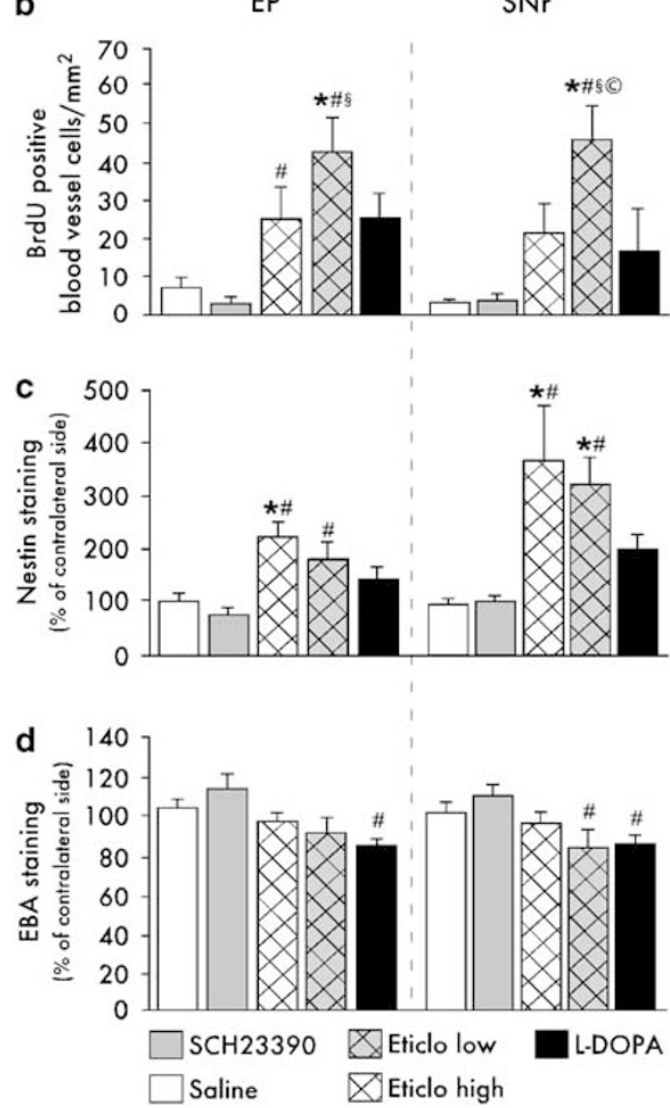

Figure 4 (a) Blockage of DI receptors with the antagonist $\mathrm{SCH} 23390$ completely abolishes L-DOPA-induced dyskinesia. Co-treatment with the D2 antagonist at a low dose $(0.01 \mathrm{mg} / \mathrm{kg}, n=7)$ had no effect on dyskinesia, whereas a higher dose $(2.0 \mathrm{mg} / \mathrm{kg}, n=7)$ had a dampening effect on the expression of AIMs. Scores are shown as a sum of axial, limb, and orolingual during each testing session (repeated-measures ANOVA: $p<0.05$ vs *saline controls $(n=12),{ }^{\#} \mathrm{SCH} 23390 \quad(n=6)$, $\bullet$ eticlopride high; $F_{(4,35)}=13.87$ ). (b) L-DOPA in adjunction to the D2 antagonist eticlopride at a high and a low dose produced an increased endothelial proliferation (BrdU/laminin-positive cells $/ \mathrm{mm}^{2}$ ), (c) upregulation of nestin immunoreactivity, and (d) loss of EBA expression in the EP and $\mathrm{SNr}$ compared with saline controls and SCH23390 (one-factor ANOVA: $p<0.05$ vs *saline controls $(n=12),{ }^{\#} \mathrm{SCH} 23390(n=6),{ }^{\S}$ L-DOPA only $(n=8),{ }^{\circ}$ eticlopride high; $\operatorname{BrdU}: F_{\operatorname{EP}(4,35)}=6.65$ and $F_{\mathrm{SNr}(4,35)}=10.50$ Nestin: $F_{\operatorname{EP}(4,33)}=4.1$ I and $\mathrm{F}_{\mathrm{SNr}(4,33)}=4.42$ EBA: $\mathrm{F}_{\mathrm{EP}(4,35)}=3.04$ and $\left.\mathrm{F}_{\mathrm{SNr}(4,37)}=3.49\right)$.

Reduction of EBA expression was only evident in the L-DOPAvehicle group in both the $\mathrm{EP}$ and the $\mathrm{SNr}$, reaching statistical significance in the former structure (Figure $5 \mathrm{~d}$; one-factor ANOVA, $p_{\mathrm{EP}}=0.044, p<0.05$ for L-DOPA only $v s$ saline).

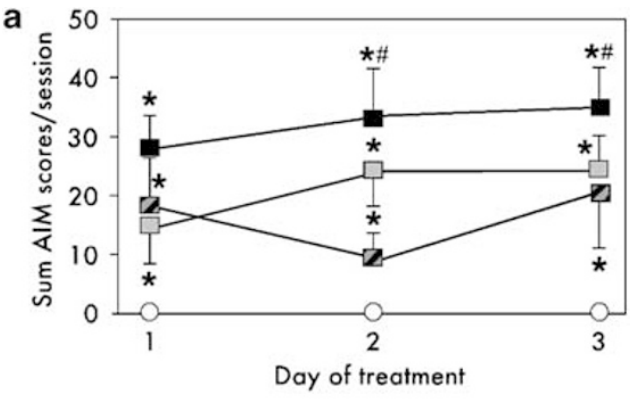

b $\quad \mathrm{EP} \quad \mathrm{SNr}$
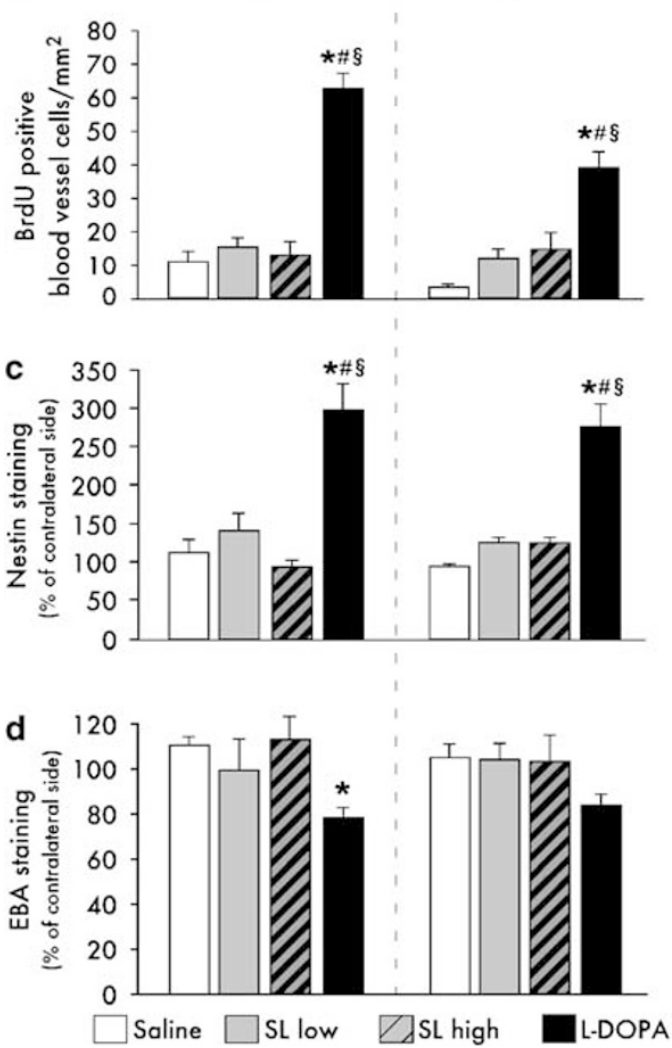

Figure 5 Effect of the systemic MEK inhibitor SL327 on dyskinesia and angiogenic activity. (a) Only the higher dose of SL327 had a significant dampening effect on the expression of dyskinesia at day 2 and 3 of treatment (repeated-measures ANOVA: $p<0.05$ vs *saline controls $(n=6)$ and ${ }^{\#}$ SL327 high dose $\left.(n=4) ; F_{(3,15)}=5.26\right)$. (b) The number of $\mathrm{BrdU} /$ laminin-positive cells was attenuated by both the low and the higher dose of SL327 compared with L-DOPA only $(n=5)$ and a similar trend was seen with (c) nestin expression on blood vessel profiles. (d) The expression of EBA was only reduced in the L-DOPA only group and rats treated with SL327 did not differ from saline in any region examined (one-factor ANOVA: $p<0.05$ vs * saline controls $(n=6),{ }^{\#}$ SL327 high dose $(n=4)$,

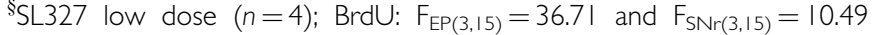
nestin: $\mathrm{F}_{\mathrm{EP}(3,15)}=7.78$ and $\mathrm{F}_{\mathrm{SNr}(3,15)}=18.18 \mathrm{EBA}: \mathrm{F}_{\mathrm{EP}(3,15)}=3.43$.

\section{DISCUSSION}

Although being the most effective treatment for PD, L-DOPA causes a development of dyskinesia and motor fluctuations in the majority of the treated patients. Longacting DA receptor agonists, of which bromocriptine is the prototype, entail a much lower incidence of dyskinesia, although they are less effective than L-DOPA in ameliorating 
PD motor symptoms (reviewed in Stowe et al, 2008). The pathophysiology of LID is multifaceted, comprising both pre-synaptic alterations in DA release and clearance and abnormal post-synaptic responses, such as supersensitive D1 receptor-dependent signaling in striatal neurons and complex changes affecting multiple, non-dopaminergic systems within the basal ganglia (reviewed in Cenci, 2007; Cenci and Lundblad, 2006). We recently reported that, in addition to neurons, the basal ganglia microvasculature shows abnormal responses in L-DOPA-treated dyskinetic rats, exhibiting endothelial proliferation and upregulation of immature endothelial markers. This angiogenic response is accompanied by actual vessel growth and altered BBB permeability in the most affected brain regions (Westin et al, 2006).

In this study, we have compared the extent of endothelial proliferation, upregulation of immature endothelial markers, and downregulation of BBB proteins in 6-OHDAlesioned rats treated with L-DOPA or bromocriptine, which has strong motor stimulant properties but does not induce AIMs in this animal model (Lindgren et al, 2007; Lundblad et al, 2002). Only L-DOPA elicited angiogenic activity in the basal ganglia, which was similar in extent and distribution to that reported in our earlier study (Westin et al, 2006). As bromocriptine-treated animals exhibited pronounced rotational behavior, these results show that an increased motor activity due to anti-parkinsonian drug treatment is not sufficient to elicit angiogenesis in the basal ganglia.

Being a direct DA receptor agonist with predominant D2 activity, as well as a low-affinity ligand at serotonergic and adrenergic receptors (Kvernmo et al, 2006; Perachon et al, 1999), bromocriptine differs significantly from L-DOPA in its mechanisms of action. We therefore addressed the role of D1-like vs D2-like dopamine receptors in the angiogenic response to L-DOPA by using selective agonists and/or antagonists for these receptor classes. In one experiment, we compared the effects of L-DOPA with those of the specific D1-like receptor agonist, SKF38393, at two different doses. The lower dose of SKF38393 $(0.5 \mathrm{mg} / \mathrm{kg})$ was subthreshold to induce dyskinesia, and did not have any effect on the expression of angiogenesis markers in the basal ganglia. The higher dose of SKF38393 (1.5 mg/kg), however, induced both dyskinesia and a microvascular response similarly to L-DOPA. These results show that for the same degree of dyskinesia, D1-like receptor agonists are as potent as L-DOPA in inducing angiogenesis within the basal ganglia.

We next compared the effects of selective D1- or D2-receptor antagonists chronically co-administered with L-DOPA. The D1-like antagonist SCH23390 completely blocked dyskinesia and all markers of angiogenesis. Very different results were produced by the D2 antagonist, eticlopride. At the dose of $0.01 \mathrm{mg} / \mathrm{kg}$, eticlopride did not modify the L-DOPA-induced AIM scores but rather potentiated the endothelial proliferation. At the higher dose $(2.0 \mathrm{mg} / \mathrm{kg})$, eticlopride reduced the severity of dyskinesia without blocking the expression of angiogenesis markers. Altogether, our results indicate that dyskinesiogenic L-DOPA treatment induces microvascular remodeling through stimulation of D1 receptors, whereas the concomitant stimulation of D2 receptors limits the extent of this response.

Pharmacological stimulation of D1 receptors causes an activation of ERK1/2 in DA-denervated striatal neurons
(Gerfen et al, 2002) and this signaling event is implicated in the development of dyskinesia (Santini et al, 2007; Schuster et al, 2008; Westin et al, 2007). Activation of ERK1/2 also plays a central role in endothelial proliferation in different model systems (reviewed in Zachary and Gliki, 2001). To verify the involvement of ERK1/2 in L-DOPA-induced angiogenesis, 6-OHDA-lesioned rats were co-treated with L-DOPA and the MEK inhibitor, SL327 (which selectively inhibits ERK activation). In line with results from a mouse model of LID (Santini et al, 2007), SL327 attenuated the AIMs. Strikingly, SL327 completely blocked the angiogenesis markers, that is, the increase in BrdU/laminin-positive cells, the upregulation of nestin, and the loss of microvessel EBA expression induced by L-DOPA. Because of its magnitude, this effect of SL327 is unlikely to be secondary to the observed (partial) reduction in dyskinesia severity. Altogether, these findings show that the microvascular and neuronal plasticity induced by L-DOPA in the parkinsonian brain share some critical mediators, and highlight the need to consider both of these responses when assessing the mechanisms of action of anti-dyskinetic interventions.

Cerebral microvessels express DA receptors (Choi et al, 2006), and the opposing effects of D1 and D2 receptor antagonists on L-DOPA-induced angiogenesis in this study are in keeping with the reported roles of D2 and D1 receptors in endothelial cell biology. Indeed, DA inhibits endothelial proliferation and vessel growth through activation of D2 receptors (Basu et al, 2001; Cristina et al, 2005; Gomez et al, 2006; Sarkar et al, 2004). By contrast, in vitro and in vivo studies have shown that D1 receptor activation stimulates adenylate cyclase and cyclic AMP (cAMP) production in endothelial cells (Bacic et al, 1991). This effect is strongly correlated to angiogenesis (Lu et al, 2008; Ristori et al, 2008). The anti-mitotic action of D2 receptors on endothelial cells (Basu et al, 2001; Cristina et al, 2005) may explain the potentiating effect of low-dose eticlopride on L-DOPAinduced angiogenesis in this study. High-dose eticlopride did not, however, produce a more marked potentiation. As the latter treatment significantly reduced the AIMs, these findings indicate that L-DOPA-induced angiogenesis is critically dependent on the neurochemical changes associated with dyskinesia, and that a direct action of L-DOPA (or DA) on the brain microvessels cannot alone explain this response. Such interpretation is supported by the specific anatomical distribution of the angiogenesis markers, which were highly expressed in the dorsolateral $\mathrm{CPu}, \mathrm{GP}, \mathrm{EP}$, and $\mathrm{SNr}$ on the side ipsilateral to the 6-OHDA lesion, being quantitatively most prominent in the latter two structures.

Being the output nuclei of the basal ganglia, the EP and the $\mathrm{SNr}$ mediate motor stimulant effects of antiparkinsonian drug treatment (Marti et al, 2004; Robertson and Robertson, 1989). In these two structures, there is a high density of D1 receptors on the terminals of 'direct pathway' (striatonigral) axon fibers (Dawson et al, 1988; Savasta et al, 1986a, b), promoting the release of both GABA and dynorphin (reviewed in Cenci and Lindgren, 2007). In addition to structural and functional similarities, the EP and $\mathrm{SNr}$ show a similar increase in the rate of 2-deoxyglucose (2-DG) uptake after treatment with L-DOPA or D1 receptor agonists (Trugman and Wooten, 1986, 1987), reflecting increased metabolic activity of axon terminals (Sokoloff et al, 1977). The angiogenic response associated with 
dyskinesia may thus represent an adaptation to locally increased metabolic demands caused by altered patterns of neuronal activity. Similar to the situation reported in other neurological conditions (Ivens et al, 2007; van Vliet et al, 2007), angiogenesis and altered BBB permeability may, however, itself contribute to the abnormal neuronal activities and (in the case of PD) it may also alter the kinetics of L-DOPA entry into the brain. In support of this contention, the development of $\mathrm{L}$-DOPA-induced AIMs can be delayed by corticosterone co-treatment (Barnum et al, 2008), which is known to inhibit brain angiogenesis (Ekstrand et al, 2008b) and to stabilize the BBB. It is presently unknown whether $\mathrm{BBB}$ dysfunction contributes to human LID. In vivo imaging studies have provided indications of BBB dysfunction in PD (Bartels et al, 2008; Kortekaas et al, 2005), but not in a progressive macaque model of LID (Astradsson et al, 2009). The occurrence of angiogenesis in this animal model was, however, not addressed.

In addition to an increased permeability, immature microvessels may show abnormal hemodynamic responses. Using positron emission tomography (PET), Hirano et al, 2008 have found that the administration of $\mathrm{L}$-DOPA causes a much larger increase in putaminal and pontine regional cerebral blood flow ( $\mathrm{rCBF}$ ) in PD patients experiencing dyskinesia compared with non-dyskinetic subjects. No difference in cerebral metabolic rate (CMR) for glucose was found on L-DOPA, pointing to a large dissociation between blood flow and glucose metabolism in dyskinetic patients (Hirano et al, 2008). The relationship between changes in $\mathrm{rCBF}$ and the angiogenesis induced by L-DOPA is presently unclear, but these phenomena are likely to share some common molecular and chemical determinants. Indeed, the D1 agonist SKF38393 causes vessel dilatation, whereas the D1 antagonist SCH23390 causes constriction of cerebral pial arterioles in vivo (Edvinsson et al, 1985). Furthermore, D1-specific agonists induce large increases in relative cerebral blood volume (rCBV) in regions of high DA receptor abundance, whereas the D1 receptor antagonist SCH23390 prevents this hemodynamic response (Choi et al, 2006).

All these findings indicate that the brain microvasculature is heavily affected by the pharmacotherapy of PD and that it may influence its outcome. Accordingly, microvascular responses ought to be considered when evaluating the effects of either anti- or pro-dyskinetic treatments with unknown mechanisms of action. Intriguingly, some vasoactive substances, such as $\alpha_{2}$-adrenergic receptor antagonists (Zou and Cowley, 2000), nicotine (Hawkins et al, 2002), and nitric oxide synthase inhibitors (Faraci and Brian, 1994) exert strong anti-dyskinetic effects in animal models of PD (Fox et al, 2001; Padovan-Neto et al, 2009; Quik et al, 2007, 2008). Elucidating the effects of these treatments on microvascular physiology and angiogenesis in the brain will be an exciting task for future studies.

\section{ACKNOWLEDGEMENTS}

We thank Ann-Christin Lindh for excellent technical assistance. This study was supported by grants from the Michael J Fox Foundation for Parkinson's Research (MAC), The Swedish Research Council (MAC), The Greta and Johan Kocks Foundation (MAC), and The Royal Physiographic Society (HSL), and by Grant number 7 R01 NS048235 from
National Institutes of Health the National Institute of Neurological Disorders and Stroke through Vanderbilt University (Nashville, TN; subcontract to MAC).

\section{DISCLOSURE/CONFLICT OF INTEREST}

The author(s) declare that, except for income received from my primary employer, no financial support or compensation has been received from any individual or corporate entity over the past 3 years for research or professional service and there are no personal financial holdings that could be perceived as constituting a potential conflict of interest.

\section{REFERENCES}

Abercrombie M, Johnson ML (1946). Quantitative histology of Wallerian degeneration: I. Nuclear population in rabbit sciatic nerve. J Anat 80(Part 1): 37-50.

Alonso G, Galibert E, Duvoid-Guillou A, Vincent A (2005). Hyperosmotic stimulus induces reversible angiogenesis within the hypothalamic magnocellular nuclei of the adult rat: a potential role for neuronal vascular endothelial growth factor. BMC Neurosci 6: 20.

Astradsson A, Jenkins BG, Choi JK, Hallett PJ, Levesque MA, McDowell JS et al (2009). The blood-brain barrier is intact after levodopa induced dyskinesias in parkinsonian primatesevidence from in vivo neuroimaging studies. Neurobiol Dis. Jun 6 (e-pub ahead of print).

Bacic F, Uematsu S, McCarron RM, Spatz M (1991). Dopaminergic receptors linked to adenylate cyclase in human cerebromicrovascular endothelium. J Neurochem 57: 1774-1780.

Bardo MT, Valone JM, Bevins RA (1999). Locomotion and conditioned place preference produced by acute intravenous amphetamine: role of dopamine receptors and individual differences in amphetamine self-administration. Psychopharmacology (Berl) 143: 39-46.

Barnum CJ, Eskow KL, Dupre K, Blandino Jr P, Deak T, Bishop C (2008). Exogenous corticosterone reduces L-DOPA-induced dyskinesia in the hemi-parkinsonian rat: role for interleukin1beta. Neuroscience 156: 30-41.

Bartels AL, Willemsen AT, Kortekaas R, de Jong BM, de Vries R, de Klerk O et al (2008). Decreased blood-brain barrier P-glycoprotein function in the progression of Parkinson's disease, PSP and MSA. J Neural Transm 115: 1001-1009.

Basu S, Nagy JA, Pal S, Vasile E, Eckelhoefer IA, Bliss VS et al (2001). The neurotransmitter dopamine inhibits angiogenesis induced by vascular permeability factor/vascular endothelial growth factor. Nat Med 7: 569-574.

Carmeliet P (2003). Angiogenesis in health and disease. Nat Med 9(Angiogenesis focus): 653-660.

Cassella JP, Lawrenson JG, Allt G, Firth JA (1996). Ontogeny of four blood-brain barrier markers: an immunocytochemical comparison of pial and cerebral cortical microvessels. J Anat 189(Part 2): 407-415.

Cavaglia M, Dombrowski SM, Drazba J, Vasanji A, Bokesch P.M, Janigro D (2001). Regional variation in brain capillary and vascular response to ischemia. Brain Res 910: 81-93.

Cenci MA (2007). Dopamine dysregulation of movement control in L-DOPA-induced dyskinesia. Trends Neurosci 30: 236-243.

Cenci MA, Lee CS, Bjorklund A (1998). -DOPA-induced dyskinesia in the rat is associated with striatal overexpression of prodynorphin- and glutamic acid decarboxylase mRNA. Eur $J$ Neurosci 10: 2694-2706.

Cenci MA, Lindgren HS (2007). Advances in understanding L-DOPA-induced dyskinesia. Curr Opin Neurobiol 17: 665-671.

Cenci MA, Lundblad M (2006). Post- vs presynaptic plasticity in L-DOPA-induced dyskinesia. J Neurochem 99: 381-392. 
Cenci MA, Lundblad M (2007). Ratings of L-DOPA-induced dyskinesia in the unilateral 6-OHDA lesion model of Parkinson's disease in rats and mice. Curr Protoc Neurosci Chapter 9, Unit 925.

Chase TN (1998). Levodopa therapy: consequences of the nonphysiologic replacement of dopamine. Neurology 50(5 Suppl 5): S17-S25.

Choi JK, Chen YI, Hamel E, Jenkins BG (2006). Brain hemodynamic changes mediated by dopamine receptors: role of the cerebral microvasculature in dopamine-mediated neurovascular coupling. Neuroimage 30: 700-712.

Cristina C, Diaz-Torga G, Baldi A, Gongora A, Rubinstein M, Low MJ et al (2005). Increased pituitary vascular endothelial growth factor-a in dopaminergic D2 receptor knockout female mice. Endocrinology 146: 2952-2962.

Dawson TM, Barone P, Sidhu A, Wamsley JK, Chase TN (1988). The D1 dopamine receptor in the rat brain: quantitative autoradiographic localization using an iodinated ligand. $\mathrm{Neu}$ roscience 26: 83-100.

Edvinsson L, McCulloch J, Sharkey J (1985). Vasomotor responses of cerebral arterioles in situ to putative dopamine receptor agonists. $\mathrm{Br} J$ Pharmacol 85: 403-410.

Ekstrand J, Hellsten J, Tingstrom A (2008a). Environmental enrichment, exercise and corticosterone affect endothelial cell proliferation in adult rat hippocampus and prefrontal cortex. Neurosci Lett 442: 203-207.

Ekstrand J, Hellsten J, Wennstrom M, Tingstrom A (2008b). Differential inhibition of neurogenesis and angiogenesis by corticosterone in rats stimulated with electroconvulsive seizures. Prog Neuropsychopharmacol Biol Psychiatry 32: 1466-1472.

Faraci FM, Brian Jr JE (1994). Nitric oxide and the cerebral circulation. Stroke 25: 692-703.

Faucheux BA, Bonnet AM, Agid Y, Hirsch EC (1999). Blood vessels change in the mesencephalon of patients with Parkinson's disease. Lancet 353: 981-982.

Fox SH, Henry B, Hill MP, Peggs D, Crossman AR, Brotchie JM (2001). Neural mechanisms underlying peak-dose dyskinesia induced by levodopa and apomorphine are distinct: evidence from the effects of the alpha(2) adrenoceptor antagonist idazoxan. Mov Disord 16: 642-650.

Frederiksen K, McKay RD (1988). Proliferation and differentiation of rat neuroepithelial precursor cells in vivo. J Neurosci 8: 1144-1151.

Gallo V, Armstrong R (1995). Developmental growth factorinduced regulation of nestin in oligodendrocyte lineage cells. J Neurosc 15: 394-406.

Gerfen CR, Miyachi S, Paletzki R, Brown P (2002). D1 dopamine receptor supersensitivity in the dopamine-depleted striatum results from a switch in the regulation of ERK1/2/MAP kinase. J Neurosci 22: 5042-5054.

Gomez R, Gonzalez-Izquierdo M, Zimmermann RC, NovellaMaestre E, Alonso-Muriel I, Sanchez-Criado J et al (2006). Low-dose dopamine agonist administration blocks vascular endothelial growth factor (VEGF)-mediated vascular hyperpermeability without altering VEGF receptor 2-dependent luteal angiogenesis in a rat ovarian hyperstimulation model. Endocrinology 147: 5400-5411.

Gundersen HJ, Jensen EB (1987). The efficiency of systematic sampling in stereology and its prediction. J Microsc 147(Part 3): 229-263.

Hawkins BT, Brown RC, Davis TP (2002). Smoking and ischemic stroke: a role for nicotine? Trends Pharmacol Sci 23: 78-82.

Hirano S, Asanuma K, Ma Y, Tang C, Feigin A, Dhawan V et al (2008). Dissociation of metabolic and neurovascular responses to levodopa in the treatment of Parkinson's disease. J Neurosci 28: 4201-4209.

Ivens S, Kaufer D, Flores LP, Bechmann I, Zumsteg D, Tomkins O et al (2007). TGF-beta receptor-mediated albumin uptake into astrocytes is involved in neocortical epileptogenesis. Brain 130(Part 2): 535-547.
Kleim JA, Cooper NR, VandenBerg PM (2002). Exercise induces angiogenesis but does not alter movement representations within rat motor cortex. Brain Res 934: 1-6.

Kortekaas R, Leenders KL, van Oostrom JC, Vaalburg W, Bart J, Willemsen AT et al (2005). Blood-brain barrier dysfunction in parkinsonian midbrain in vivo. Ann Neurol 57: 176-179.

Kvernmo T, Hartter S, Burger E (2006). A review of the receptorbinding and pharmacokinetic properties of dopamine agonists. Clin Ther 28: 1065-1078.

LaHoste GJ, Marshall JF (1990). Nigral D1 and striatal D2 receptors mediate the behavioral effects of dopamine agonists. Behav Brain Res 38: 233-242.

Larsen JO, Gundersen HJ, Nielsen J (1998). Global spatial sampling with isotropic virtual planes: estimators of length density and total length in thick, arbitrarily orientated sections. J Microsc 191: 238-248.

Lees AJ, Stern GM (1981). Sustained bromocriptine therapy in previously untreated patients with Parkinson's disease. J Neurol Neurosurg Psychiatry 44: 1020-1023.

Lindgren HS, Rylander D, Ohlin KE, Lundblad M, Cenci MA (2007). The 'motor complication syndrome' in rats with 6-OHDA lesions treated chronically with L-DOPA: relation to dose and route of administration. Behav Brain Res 177: $150-159$.

Lu C, Pelech S, Zhang H, Bond J, Spach K, Noubade R et al (2008). Pertussis toxin induces angiogenesis in brain microvascular endothelial cells. J Neurosci Res 86: 2624-2640.

Lundblad M, Andersson M, Winkler C, Kirik D, Wierup N, Cenci MA (2002). Pharmacological validation of behavioural measures of akinesia and dyskinesia in a rat model of Parkinson's disease. Eur J Neurosci 15: 120-132.

Marti M, Mela F, Veronesi C, Guerrini R, Salvadori S, Federici M et al (2004). Blockade of nociceptin/orphanin FQ receptor signaling in rat substantia nigra pars reticulata stimulates nigrostriatal dopaminergic transmission and motor behavior. I Neurosci 24: 6659-6666.

Mokry J, Nemeneck S (1999). Cerebral angiogenesis shows nestin expression in endothelial cells. Gen Physiolo Biophys 18(Suppl 1): 25-29.

Monville C, Torres EM, Dunnett SB (2005). Validation of the L-Dopa-induced dyskinesia in the 6-OHDA model and evaluation of the effects of selective dopamine receptor agonists and antagonists. Brain Res Bull 68: 16-23.

Padovan-Neto FE, Echeverry MB, Tumas V, Del-Bel EA (2009). Nitric oxide synthase inhibition attenuates L-DOPA-induced dyskinesias in a rodent model of Parkinson's disease. Neuroscience 159: 927-935.

Paxinos G, Watson C (1998). The Rat Brain in Stereotaxic Coordinates. Academic Press Inc: San Diego, California.

Pearce RK, Banerji T, Jenner P, Marsden CD (1998). De novo administration of ropinirole and bromocriptine induces less dyskinesia than L-dopa in the MPTP-treated marmoset. Mov Disord 13: 234-241.

Perachon S, Schwartz JC, Sokoloff P (1999). Functional potencies of new antiparkinsonian drugs at recombinant human dopamine D1, D2 and D3 receptors. Eur J Pharmacol 366: 293-300.

Pollack AE, Fink JS (1996). Synergistic interaction between an adenosine antagonist and a D1 dopamine agonist on rotational behavior and striatal c-Fos induction in 6-hydroxydopaminelesioned rats. Brain Res 743: 124-130.

Quik M, Cox H, Parameswaran N, O'Leary K, Langston JW, Di Monte D (2007). Nicotine reduces levodopa-induced dyskinesias in lesioned monkeys. Ann Neurol 62: 588-596.

Quik M, O'Leary K, Tanner CM (2008). Nicotine and Parkinson's disease: implications for therapy. Mov Disord 23: 1641-1652.

Rascol A, Guiraud B, Montastruc JL, David J, Clanet M (1979). Long-term treatment of Parkinson's disease with bromocriptine. J Neurol Neurosurg Psychiatry 42: 143-150. 
Ristori C, Ferretti ME, Pavan B, Cervellati F, Casini G, Catalani E et al (2008). Adenylyl cyclase/cAMP system involvement in the antiangiogenic effect of somatostatin in the retina. Results from transgenic mice. Neurochem Res 33: 1247-1255.

Robertson GS, Robertson HA (1989). Evidence that L-dopainduced rotational behavior is dependent on both striatal and nigral mechanisms. J Neurosci 9: 3326-3331.

Rosenstein JM, Mani N, Silverman WF, Krum JM (1998). Patterns of brain angiogenesis after vascular endothelial growth factor administration in vitro and in vivo. Proc Natl Acad Sci USA 95: 7086-7091.

Santini E, Valjent E, Usiello A, Carta M, Borgkvist A, Girault JA et al (2007). Critical involvement of cAMP/DARPP-32 and extracellular signal-regulated protein kinase signaling in L-DOPAinduced dyskinesia. J Neurosci 27: 6995-7005.

Sarkar C, Chakroborty D, Mitra RB, Banerjee S, Dasgupta PS, Basu S (2004). Dopamine in vivo inhibits VEGF-induced phosphorylation of VEGFR-2, MAPK, and focal adhesion kinase in endothelial cells. Am J Physiol Heart Circ Physiol 287: H1554-H1560.

Savasta M, Dubois A, Benavides J, Scatton B (1986a). Different neuronal location of [3H]SCH 23390 binding sites in pars reticulata and pars compacta of the substantia nigra in the rat. Neurosci Lett 72: 265-271.

Savasta M, Dubois A, Scatton B (1986b). Autoradiographic localization of $\mathrm{D} 1$ dopamine receptors in the rat brain with [3H]SCH 23390. Brain Res 375: 291-301.

Schindler CW, Carmona GN (2002). Effects of dopamine agonists and antagonists on locomotor activity in male and female rats. Pharmacol Biochem Behav 72: 857-863.

Schuster S, Nadjar A, Guo JT, Li Q, Ittrich C, Hengerer B et al (2008). The 3-hydroxy-3-methylglutaryl-CoA reductase inhibitor lovastatin reduces severity of L-DOPA-induced abnormal involuntary movements in experimental Parkinson's disease. J Neurosci 28: 4311-4316.

Sokoloff L, Reivich M, Kennedy C, Des Rosiers MH, Patlak CS, Pettigrew KD et al (1977). The [14C]deoxyglucose method for the measurement of local cerebral glucose utilization: theory, procedure, and normal values in the conscious and anesthetized albino rat. J Neurochem 28: 897-916.

Stowe RL, Ives NJ, Clarke C, van Hilten J, Ferreira J, Hawker RJ et al (2008). Dopamine agonist therapy in early Parkinson's disease. Cochrane Database Syst Rev 2: CD006564.
Swain RA, Harris AB, Wiener EC, Dutka MV, Morris HD, Theien $\mathrm{BE}$ et al (2003). Prolonged exercise induces angiogenesis and increases cerebral blood volume in primary motor cortex of the rat. Neuroscience 117: 1037-1046.

Taylor JL, Bishop C, Walker PD (2005). Dopamine D1 and D2 receptor contributions to L-DOPA-induced dyskinesia in the dopamine-depleted rat. Pharmacol Biochem Behav 81: 887-893.

Trugman JM, Wooten GF (1986). The effects of L-DOPA on regional cerebral glucose utilization in rats with unilateral lesions of the substantia nigra. Brain Res 379: 264-274.

Trugman JM, Wooten GF (1987). Selective D1 and D2 dopamine agonists differentially alter basal ganglia glucose utilization in rats with unilateral 6-hydroxydopamine substantia nigra lesions. J Neurosci 7: 2927-2935.

van Vliet EA, da Costa Araujo S, Redeker S, van Schaik R, Aronica E, Gorter JA (2007). Blood-brain barrier leakage may lead to progression of temporal lobe epilepsy. Brain 130(Part 2): 521-534.

Westin JE, Lindgren HS, Gardi J, Nyengaard JR, Brundin P, Mohapel $\mathrm{P}$ et al (2006). Endothelial proliferation and increased blood-brain barrier permeability in the basal ganglia in a rat model of 3,4-dihydroxyphenyl-L-alanine-induced dyskinesia. J Neurosci 26: 9448-9461.

Westin JE, Vercammen L, Strome EM, Konradi C, Cenci MA (2007). Spatiotemporal pattern of striatal ERK1/2 phosphorylation in a rat model of L-DOPA-induced dyskinesia and the role of dopamine D1 receptors. Biol Psychiatry 62: 800-810.

Yasuda T, Fukuda-Tani M, Nihira T, Wada K, Hattori N, Mizuno Y et al (2007). Correlation between levels of pigment epitheliumderived factor and vascular endothelial growth factor in the striatum of patients with Parkinson's disease. Exp Neurol 206: 308-317.

Zacchigna S, Lambrechts D, Carmeliet P (2008). Neurovascular signalling defects in neurodegeneration. Nat Rev Neurosci 9: 169-181.

Zachary I, Gliki G (2001). Signaling transduction mechanisms mediating biological actions of the vascular endothelial growth factor family. Cardiovasc Res 49: 568-581.

Zou AP, Cowley Jr AW (2000). Alpha(2)-adrenergic receptormediated increase in NO production buffers renal medullary vasoconstriction. Am J Physiol Regul Integr Comp Physiol 279: R769-R777.

Supplementary information accompanies the paper on the Neuropsychopharmacology website (http://www.nature.com/npp) 